\title{
Systematic screening for cervical cancer in Dakar region: prevalence and correlation with biological and socio-demographic parameters
}

Dominique Diouf ${ }^{1,2,3,4^{*}}$, Gora Diop ${ }^{4,5,6}$, Cheikh Ahmadou Tidian Diarra², Aminata Issa Ngom ${ }^{1}$, Khadija Niane ${ }^{6}$, Moussa Ndiaye ${ }^{6}$, Sidy Ka $\mathrm{K}^{2,4}$, Oumar Faye $\mathrm{e}^{1,3,4}$ and Ahmadou Dem

\begin{abstract}
Background: Cervical cancer is a major public health problem. In 2018, globally 569,847 cervical cancer were diagnosed and 311,000 deaths were projected due to this preventable disease. Worldwide, therefore, the cervical cancer disease ranks as the fourth most frequently diagnosed cancer and the fourth leading cause of cancer death in women in 2018.

The high rate of dysplasia in Senegal and the absence of well-organized screening programs informed this study, which aims to determine the prevalence of cervical dysplasia and its relationship to biological and sociodemographic characteristics.

Methods: This study is based on 1000 conventional smears collected during routine cervical cancer screening at the Gaspard Camara Health Center and the Histology - Embryology and Cytogenetics Laboratory of the Cheikh Anta DIOP University in Dakar. The smears were read according to the Bethesda and Richart systems. However, all data were returned to the Bethesda system using the correspondence table between the different classifications of squamous cell lesions of the cervix. Some of the patients with abnormal smears had colposcopy and if necessary a biopsy. Other patients with low-grade lesions were recommended to have their smears resumed in 6 months or 1 year later.

\footnotetext{
* Correspondence: dominiquediouf2002@gmail.com

'Laboratory of cytogenetic and reproductive biology, Hopital Aristide-Le-Dantec, Pasteur Avenue, PO Box 3001, Dakar, Senegal

${ }^{2}$ Institut-Juliot-Curie, Hospital Aristide Le Dantec, Pasteur Avenue, PO Box 3001, Dakar, Senegal

Full list of author information is available at the end of the article
}

(c) The Author(s). 2020 Open Access This article is licensed under a Creative Commons Attribution 4.0 International License, which permits use, sharing, adaptation, distribution and reproduction in any medium or format, as long as you give appropriate credit to the original author(s) and the source, provide a link to the Creative Commons licence, and indicate if changes were made. The images or other third party material in this article are included in the article's Creative Commons licence, unless indicated otherwise in a credit line to the material. If material is not included in the article's Creative Commons licence and your intended use is not permitted by statutory regulation or exceeds the permitted use, you will need to obtain permission directly from the copyright holder. To view a copy of this licence, visit http://creativecommons.org/licenses/by/4.0/ The Creative Commons Public Domain Dedication waiver (http://creativecommons.org/publicdomain/zero/1.0/) applies to the data made available in this article, unless otherwise stated in a credit line to the data. 
(Continued from previous page)

Results: Cytological analysis was performed for 1000 patients aged 16 to 82 years (mean age $=41 \pm 11.16$ ). Among these, 176 patients had abnormal smears, 23 had Atypical Squamous Cells of Undetermined Significance (ASCUS), 143 had a low-grade lesion, 9 had a high-grade lesion and 1 had carcinoma. Among the remaining 822 patients, cytological analysis revealed no suspected malignant lesions, but 623 among them had dystrophy and 2 were unsatisfactory. Among patients with abnormal smears, 104 patients (23 ASCUS +71 low grade +9 high grade +1 carcinoma) had performed colposcopy, 40 of whom had normal colposcopy and 64 had abnormalities. Sixty-four (64) biopsies were performed. Four (4) were not satisfactory. However, for 26/60 biopsies, the histology was normal, 21/60 had a low grade, 11 displayed a high grade and only 2 had carcinoma. Among the 176 patients with abnormal smears, 72 low-grade patients had undergone cytological examination 6 months to 1 year later to determine the persistence, regression or progression of low-grade dysplasia. During follow-up, persistence was observed in $25 \%$ ( $n=18$ ) of cases, progression to High-grade squamous intraepithelial lesion (HSIL) was detected in $2.78 \%(n=2)$, while $72.22 \%(n=52)$ of the patients experienced regression.

Conclusion: In this study, the prevalence of abnormal smear was $17.60 \%$ for cytology. Meanwhile, the Colposcopy and histology confirmed just 3.40\%. These results underline the interest and need for a review of the discrepancies observed between pathologists.

Keywords: Cervical cancer, Dysplasia, Epidemiology, Prevalence, Senegal

\section{Introduction}

According to the latest estimates, cervical cancer remains the fourth most frequently diagnosed cancer and the fourth leading cause of cancer death in women in 2018 , with an estimate of 570,000 cases and 311,000 deaths [1].

Most cases of cervical cancer occur in developing countries where control and screening programs remain ineffective. In contrast, in developed countries, implementation of programs has led to a significant reduction in incidence and mortality [2-4]. Since the introduction of organized cervical screening in the 1960's in the U.S., incidence and mortality from cervical cancer have declined by $75 \%$, however, this decline is not uniform [5].

In Africa, cervical cancer is the most common cancer among women, with a high prevalence in the 15 to 44 age group. Most of them belong to the most disadvantaged population $[6,7]$. More than $90 \%$ of all observed cervical cancer cases are related to persistent high-risk human papillomavirus (HPV-HR) infection, resulting in precancerous lesions that can progress to invasive cervical cancer if left untreated [6, 8].

About 40 genotypes infect the genital tract and are classified according to their oncogenic potentials. The high-risk types are HPV-16 and HPV-18. They are responsible for about $70 \%$ of cervical cancer cases $[9,10]$.

Cervical cancer is on the increase in sub-Saharan Africa, with more than 75,000 new cases and 50,000 deaths per year which is aggravated by HIV infection [11].

In Senegal, cervical cancer is the leading cause of female cancer deaths with an estimated 1876 cases diagnosed annually, of which 1367 cases (72.90\%) are fatal [12].

The objective of this study, which is strictly limited to Dakar region, was to provide a prevalence of cervical dysplasia in Senegal from 1000 systematically screened patients and to correlate the results with biological and socio-demographic characteristics. Further, we aimed to examine the concordance between cytological and histological analysis and to evaluate persistency, progression and regression in patients with low-grade dysplasia.

\section{Material and methods \\ Study population and sample collection}

From January 2015 to December 2018, 1000 cervical smears were collected and analyzed from Senegalese women aged 16 to 82 years, who participated in a voluntary screening at the Histology - Embryology and Cytogenetics Laboratory of the Cheikh Anta Diop University of Dakar (UCAD) $(n=357)$ and the Gaspard Camara Health Center $(n=643)$ (Table 1$)$. Informed consent was obtained from all patients. The study subjects were interviewed using a structured questionnaire that took into account socio-demographic and reproductive characteristics such as: age, education level, occupation, marital status, place of residence, contraceptive use, depigmentation, pregnancy and parity (Table 1). The local research ethics committee of Cheikh Anta DIOP University (UCAD) approved this study under the Protocol 019412016 / CER/UCAD.

\section{Cytology}

In Senegal, the conventional method remains the Papanicolaou test, which is the most widely used method in screening programs [13]. However, the access to the Pap test is very limited except in certain highly urban settings.

All women were screened for abnormal cervical cytology using the conventional Papanicolaou smear. The 
Table 1 Socio-demographic and reproductive characteristic of participants $(n=1000)$

\begin{tabular}{|c|c|}
\hline Socio-demographic characteristics & Values N (\%) \\
\hline \multicolumn{2}{|l|}{ Age (yrs) } \\
\hline $16-29$ & $162(16.20)$ \\
\hline $30-39$ & $299(29.90)$ \\
\hline $40-49$ & $321(32.10)$ \\
\hline $50-59$ & $161(16.10)$ \\
\hline Above 60 & $57(5.70)$ \\
\hline Mean age \pm SD & $41 \pm 11.16$ \\
\hline \multicolumn{2}{|l|}{ Education } \\
\hline Low level & $876(87.60)$ \\
\hline High level & $124(12.40)$ \\
\hline \multicolumn{2}{|l|}{ Education level } \\
\hline No formal education & $289(28.90)$ \\
\hline Primary level & $273(27.30)$ \\
\hline Secondary level & $314(31.40)$ \\
\hline Higher level and above & $124(12.40)$ \\
\hline \multicolumn{2}{|l|}{ Parity } \\
\hline 0 & $99(9.90)$ \\
\hline $1-2$ & $327(32.70)$ \\
\hline$>2$ & $57457.40)$ \\
\hline \multicolumn{2}{|l|}{ Gestity } \\
\hline 0 & $67(6.70)$ \\
\hline $1-2$ & $265(26.50)$ \\
\hline$>2$ & $668(66.80)$ \\
\hline
\end{tabular}

\section{Contraceptive use}

No

Hormonal

Non hormonal

\section{Skin lightning}

No

Yes

\section{Occupation}

Unemployed

Employed

Self-employed

Marital status

Single

Divorced/Separated

Widow

Married (husband monogamous)

Married (husband polygamous)

Data shown are number (\%) except otherwise specified, SD: standard deviation cells were collected with a spatula, placed on a glass microscope slide and then, fixed with a spray. The smear readings were taken using the Bethesda and Richart systems. The concordance between the different classifications of squamous cell lesions of the cervix made it possible to bring all the results of the reading back to the Bethesda system, represented as follows: Normal, Atypical Squamous cells of undetermined significance (ASCUS), Low-grade squamous intraepithelial lesion (LSIL), High-grade squamous intraepithelial lesion (HSIL) and carcinoma [14].

\section{Histology, colposcopy and control smears}

Following the cervical smear, some patients with lowgrade dysplasia were advised to take a control smear 6 months or a year later, while others were directly referred for colposcopy. Patients with abnormal colposcopy had undergone a biopsy. Those whose control smears revealed persistent dysplasia underwent colposcopy and biopsy if necessary at the cancer department of Aristide le Dantec Hospital (Curie-HALD). For those whose smears revealed HSIL, colposcopy and, if necessary, a biopsy was performed. The samples were analyzed at the histopathology laboratory of "Hôpital Principal" or at Aristide le Dantec Hospital to confirm or invalidate the grade of the lesion revealed by the smear. Patients with LSIL who had not undergone colposcopy were received at the Gaspard Camara Health Center for a control smear.

\section{Statistical analysis}

403 (40.30) Statistical assessment was carried out using Statistical 491 (49.10) Package for the Social Sciences (SPSS) version 20.0 (IBM 106 (10.60) Corp., Armonk, NY, USA). Prevalence was determined using percentages and cross-tabulations were used to describe the association of potential risk factors with an abnormal cytological result. The $x^{2}$ test was used for the qualitative variables. Concordance between cytology and histology was tested using Kappa statistics.

The relationship of abnormal cervical cytology with potential risk factors: Age, contraceptive use, education, parity, gestity, skin lightening was analyzed using a multivariate logistic regression. The results were considered statistically significant if the $p$-value of logistic regression coefficient were $<0.05$.

\section{Results}

\section{Socio-demographic characteristics}

Table 1 summarizes the socio-demographic characteristics of 1000 patients included in the study. In summary, the range of patient age is from 16 to 82 years, with an average age of $41 \pm 11.16$ years. The age group with the largest number of participants was the 40-49 age bracket with $32.10 \%$ enrolled patients. The percentage of 
those with no form of education was 28.90 and among the literates, $27.30 \%$ could barely read and could not write.

Among the participants, $66.80 \%$ had 2 or more pregnancies and $57.40 \%$ had 2 or more children. Regarding contraception, $49.10 \%$ used the hormonal method, $10.60 \%$ used non-hormonal contraception, while $40.30 \%$ did not use contraception.

\section{Cytology}

The smear analysis was performed on 1000 samples, and two were unsatisfactory. Among the total smears, 176 had abnormal pap smear, 822 were normal or dystrophic. Smear abnormalities included 23 ASCUS, 143 low-grade squamous intraepithelial lesions (LSIL), 9 high-grade squamous intraepithelial lesions (HSIL) and 1 squamous cell carcinoma (Table 2). The highest rate of abnormal smears was noted in older women (50-59 years old; $24.80 \%)$. The mean age of women with a normal smear was $41 \pm 11.03$ years, while the mean age of women with an abnormal smear was $43.08 \pm 11.55$ years.

\section{Histology and colposcopy}

Among the patients with low-grade lesions (LSIL) and patients with ASCUS, 104 had performed colposcopy among which, 40 were normal and 64 had abnormalities. Further, biopsies were carried out on those displaying abnormalities. Four (4) were unsatisfactory, 12 had normal histology, 10 patients had cervicitis, 4 had a polyp, 21 had a low-grade lesion, 11 had a high-grade lesion and 2 had carcinoma (Table 3 ).

\section{Multivariate correlation of different variables with cytology results}

Table 4 shows the distribution of dysplasia according to the different parameters studied. The percentage of abnormal smears was higher among multiparous women $(13.42 \%)$, those who used contraception $(12.02 \%)$ and those who practiced depigmentation $(9.01 \%)$ in that

Table 2 Cytology reports

\begin{tabular}{ll}
\hline Tests (Cytology) & Values N(\%) \\
\hline Unsatisfactory smears & 2 \\
Normal smears & $199(19.93)$ \\
Inflammatory smears & $623(62.30)$ \\
ASCUS & $23(2.30)$ \\
Low grade (LSIL) & $143(14.32)$ \\
High grade (HSIL) & $9(0.90)$ \\
Carcinoma & $1(0.10)$ \\
Total cytology & $1000(100)$
\end{tabular}

The data displayed is in number (\%). HSIL: high-grade squamous intraepithelial lesion; LSIL: low-grade squamous intraepithelial lesion; ASCUS Atypia of squamous cells of undetermined significance
Table 3 Histology reports

\begin{tabular}{ll}
\hline Tests (Histology) & Values N(\%) \\
\hline Unsatisfactory samples & 4 \\
Cervicitis & $10(16.66)$ \\
Polyps & $4(6.66)$ \\
Normal & $12(20)$ \\
Low grade (LSIL) & $21(35)$ \\
High grade (HSIL) & $11(18.33)$ \\
Carcinoma & $2(3.33)$ \\
Total biopsy & $64(100)$ \\
\hline
\end{tabular}

The data displayed is in number (\%). HSIL High-grade squamous intraepithelial lesion; LSIL Low

grade squamous intraepithelial lesion

order. Statistical analysis (logistic regression) of the data showed that age and contraceptive use had significant values with a $p$-value of $p=0.0024$ and $p=0.005$ respectively.

\section{Persistency, progression and regression of LSIL}

In this study, 72 patients with low-grade dysplasia were referred to the Gaspard Camara Health Center for a

Table 4 Multivariate analysis (logistic regression) of different variables with cytology report $(N=998)$

\begin{tabular}{|c|c|c|c|}
\hline \multirow[t]{2}{*}{ Characteristics } & \multicolumn{2}{|c|}{ Cervical Cytology } & \multirow[t]{2}{*}{$P$-value } \\
\hline & $\begin{array}{l}\text { Abnormal } \\
(n=176)\end{array}$ & $\begin{array}{l}\text { Normal } \\
(n=882)\end{array}$ & \\
\hline Age (yr) & & & 0.0024 \\
\hline$<45$ & $50(5.01)$ & $288(28.85)$ & \\
\hline$\geq 45$ & $126(12.62)$ & $534(53.50)$ & \\
\hline Education & & & 0.82 \\
\hline High Level & $21(2.10)$ & 103(10.32) & \\
\hline Low Level & $155(15.53)$ & $719(72.04)$ & \\
\hline Parity & & & 0.99 \\
\hline $0-2$ & $42(4.20)$ & 209(20.94) & \\
\hline$>2$ & $134(13.42)$ & $613(61.42)$ & \\
\hline Gestity & & & 0.53 \\
\hline $0-2$ & $42(4.20)$ & $207(20.74)$ & \\
\hline$\geq 2$ & 134(13.42) & $615(61.62)$ & \\
\hline Skin lightning & & & 0.05 \\
\hline Yes & $90(9.01)$ & $482(48.29)$ & \\
\hline No & $86(8.61)$ & $340(34.06)$ & \\
\hline Contraceptive use & & & 0.005 \\
\hline Users & $120(12.02)$ & 473(47.39) & \\
\hline Non-users & $56(5.61)$ & $349(34.96)$ & \\
\hline Marital status & & & 0.30 \\
\hline Married & $155(15.53)$ & 699(70.04) & \\
\hline No Married & $21(2.10)$ & $123(12.32)$ & \\
\hline
\end{tabular}

Data shown are number (\%) not otherwise specified 
control smear 6 months or 1 year later to determine the persistence, regression or progression of dysplasia. During follow-up, persistency was observed in 25\% $(n=18)$ of cases, progression to HSIL in $2.77 \%(n=2)$ and regression in $72.22 \%(n=52)$ of patients (Table 5$)$.

\section{Discussion}

With an estimated 570,000 cases and 311,000 deaths in 2018 worldwide, this disease ranks as the fourth most frequently diagnosed cancer and the fourth leading cause of cancer death in women. The highest regional incidence and mortality rates are seen in Africa with rates elevated in Southern Africa (43.1 per 100.000), Eastern Africa (40.1 per 100.000), and Western Africa (29.6 per 100.000) [1].

Senegal ranks 17th in the world for the incidence of cervical cancer, which is the leading cause of cancer death among women in the country $[1,15]$.

The estimated participation rate for cervical cancer screening in Senegal is very low (6.90\% of women aged 18 to 69), especially in rural areas and among older groups (only $1.90 \%$ of women over 40 ). There is no reliable estimate of the prevalence of cervical dysplasia or risk factors for cervical dysplasia specific to Senegal in rural areas $[15,16]$.

In our study, the average age of the patients was $41 \pm$ 11.16 years and the most represented age group in our cohort was $40-49$ years $(32.10 \%)$. It should be noted that $66.12 \%$ of the patients were between 36 and 82 years of age. These data are similar to those of previous studies such as those of Sy-Diallo et al. [17] and Mbaye et al. et al. [18], which found an average age of $41.1 \pm 11$ years and 42.1 years respectively. However, this average age is higher than what was obtained by DEM et al. [19] in a study of squamous cell carcinomas conducted at Aristide le Dantec Hospital.

The majority of the patients had no formal education or are of low academic level $(87.60 \%)$ and more than half of the participants were multiparous $(57.40 \%)$ with at least 2 children. Nearly $60 \%$ of patients were using birth controls and $57.40 \%$ were depigmenting (Table 1). These socio-demographic characteristics of our cohort differ from those of the study conducted by Somé et al. [20] where patients were younger with $69 \%$ being under 45 years of age. In addition, they did not perform depigmentation, however, most patients were multiparous.

The prevalence of dysplasia estimated by cytology was $17.60 \%$, which is similar to the results of previous studies

Table 5 Control smear results for LSIL patients

\begin{tabular}{|c|c|c|c|c|c|c|c|}
\hline \multicolumn{2}{|c|}{ Cytology } & \multicolumn{2}{|c|}{ Persistency } & \multicolumn{2}{|c|}{ Progression } & \multicolumn{2}{|c|}{ Regression } \\
\hline$n$ & $\%$ & $n$ & $\%$ & $n$ & $\%$ & $n$ & $\%$ \\
\hline 72 & 100 & 18 & 25 & 2 & 2.78 & 52 & 72.22 \\
\hline
\end{tabular}

LSIL Low-grade squamous intraepithelial lesions such as those conducted by Afoutou et al. (16.34\%), Diallo et al. (21.03\%), Xi LF et al. (20.10\%) [21-23]. However, the rates found by Somé et al. (5.20\%) and SYDIALLO et al. (7.50\%) were lower $[17,20]$. These differences could be explained by the origin of the patients who, in our study, were concentrated in the urban areas of Dakar, unlike the studies conducted by Somé et al. [20] and Sy-Diallo et al. [17] who recruited their patients from rural areas.

This suggests that the rate of dysplasia is higher in urban than in rural areas. Another cofactor to be considered is the age of the patients. In the study of Somé et al. [20], patients were younger (69\%) and are under 45 years of age). However, most studies conducted in Senegal confirm a relationship between an increase in the prevalence of dysplasia and the age of the patients $[17,19,21]$.

In this study, age $(p=0.0024)$ and contraceptive use $(p=0.005)$ parameters were identified as being associated with the occurrence of dysplasia or carcinoma. Other parameters such as depigmentation $(p=0.05)$ were associated but not statistically significant. We did not found a link between parity, education, as well as marital status, and the occurrence of dysplasia. These results are consistent with results of studies conducted by Kassa RT. [24]; Zidi et al. [25]; Iverson et al. [26]; Roura et al. [27]; Vaisy et al. [28] that found a relationship between age, contraceptive use and the occurrence of dysplasia or cancer. However, these results contrast with those found by Paweena et al. [29]; Somé et al. [20] who did not identify contraception and age as a risk factors. On the other hand, Niresh et al. [30] found an association between age and cervical cancer but not with contraception.

Among the 176 patients with dysplasia or cancer, 104 underwent colposcopy and 72 had a control smear. Among the 104 patients, 40 had normal colposcopy while the remaining 64 had a biopsy (4 biopsies were unsatisfactory). Biopsy analyses showed 34 histological abnormalities out of 60 (low-grade intraepithelial lesions $=21$, high-grade intraepithelial lesions $=11$, Carcinoma $=2$ ).

The poor Kappa coefficient $(\mathrm{k} \leq 0.00)$ found in our study shows a lack of cyto-histological agreement among LSILs. These findings are lower than that found by Manzo-Banales et al. [31]; Melinte-Popescu et al. [32]; Oh et al. [33]; Islam et al. [34]; Önder et al. [35]. However the kappa coefficient found in this current study is similar with that found in the study conducted by Dasari et al. [36].

These differences could be explained in part by the duration patients with abnormal cytology delayed before being called for a biopsy, sometimes with 6 months to 1 year or more, which could lead to a regression of LSIL 
largely or a progression to HSIL. This difference could also be explained by technical problems related to the quality of the sample or errors related to reading or staining. These shortcomings could also be justified, in part, by the lack of funding to cover the costs of histology and the availability of colposcope.

Previous studies have shown that the use of simple colposcopy at follow-up has low sensitivity [37]. It has been shown that $70 \%$ of LSIL lesions regress by themselves; however, $10 \%$ progress to HSIL [38, 39].[. Similarly, Shaki Ö et al. [40] found somewhat similar results with persistence of $22 \%$, progression of $9 \%$ and regression of $68 \%$. These results are in agreement with those found in our study where LSIL cases decreased by $72.20 \%$ and the progression rate are $2.70 \%$. Regarding the persistence of dysplasia, which is one of the main causes of cancer occurrence, it is $25 \%$ in our study. However, other authors have found different results. Indeed, Cortes et al. [41] observed a spontaneous regression of LSIL in $50 \%$ of patients and a progression of HSIL in 6\% during the 2 years of follow-up [42], and found an $18 \%$ progression, $74 \%$ persistence and $8 \%$ regression in cases of low-grade lesions (LSIL). While Pretorius et al. [43] found a 57\% regression in LSIL cases, $32 \%$ persistence and $11 \%$ progression in HSIL. These differences in the results obtained could be justified by the duration of the follow-ups, which may vary from one author to another.

Following all these observations, it is certain that Papanicolaou smear repetition is recommended for LSIL patients $[44,45]$. Those with persistent LSIL undergo cryotherapy; high-grade profiles undergo conization or hysterectomy, while those with carcinoma have been treated with radiotherapy and/or chemotherapy.

This study has some limitations: The study was limited mostly to patients residing in the urban area of Dakar, which does not provide information at the national level. Other limitations are the long time between cytology, histology experiments and the heterogeneous reading of pap smears. According to cyto-pathologists, the reading is done according to Richart or Bethesda method. To correct this, all the data obtained were returned to the Bethesda system, using the agreement table between the different classifications of squamous cell lesions of the cervix [14].

\section{Conclusion}

In conclusion, the observation of this study raises a concern about the burden of cervical cancer in Dakar, where reliable statistics on cervical cancer are limited, despite this study showing the high prevalence of cervical dysplasia'.

Based on cytological analysis, we found an overall prevalence of $17.60 \%$ of abnormal smears. However, histology and colposcopy confirmed $3.40 \%$ of abnormality on all smears, which shows a poor concordance between cytology and histology that could be linked to the high rate of regression of LSIL before the biopsy.

The study of cofactors in the occurrence of cervical dysplasia or cervical cancer showed that patients who used contraception were more at risk of developing cervical dysplasia. The study shows also that older women have the highest risk of developing cervical cancer, and most low-grade lesions (LSIL) spontaneously regress while a small proportion progresses to high-grade dysplasia. The authors believe that new methods for evaluating cervical pathologies, such as liquid cytology, will reduce false negatives and positives and eliminate current uncertainties. In addition, the introduction of biomarkers associated with cytology such as P16ink4A/ Ki67 would reduce the number of patients referred for histology while providing better diagnostic accuracy.

\section{Abbreviations \\ ASCUS: Atypical squamous cells of undetermined significance; HSIL: High- grade squamous intraepithelial lesion; LSIL: Low-grade squamous intraepithelial lesion; HPV-HR: High-risk human papillomavirus (HPV-HR); HIV: Human immuno-deficience virus; UCAD: University cheek anta diop; CER: Centre d'études et de Recherche; HALD: Hopital aristide le dantec; \\ SPSS: Statistical package for the social sciences; RR: Relative risk; \\ $\mathrm{Cl}$ : Confidence interval}

\section{Acknowledgements \\ I would like to thank all those who supported me in making this article possible in particular, all patients included. Thanks are also due to Dr. Souleymane SARR anapathologist from the Anatomopathology Laboratory of Hospital Principal as well as the technicians, Prof. Seynabou LO, Professor at the University of St Louis, Diougouna Sissokho, midwife teacher at the maternity ward of Yeumbeul (District of Dakar Capitol, Senegal).}

\section{Authors' contributions}

DD wrote the paper and discussed results; DD, NAI, NK, NM collected samples; DCAT and KS did the colposcopy and biopsy. FO did the reading and interpretation of pap smars; OF and DA designed the study; DG, OF and DA supervised all experiments performed. DD, DG, FO and DA discussed and interpreted the final text of the manuscript. All participants contributed commentary on and corrected the manuscript. All authors read and approved the final manuscript.

Funding

Self-funded.

Availability of data and materials

The datasets used and/or analyzed during the current study are available from the corresponding author upon reasonable request.

Ethics approval and consent to participate

This study was reviewed and approved by the Comité National d'Ethique pour la Recherche en Santé (CNERS) of Senegal under the ethic certificate number 0194/2016/CER/UCAD. Study participants who agreed to participate gave written informed consent.

Consent for publication

Not applicable.

Competing interests

The authors declared no competing interests. 


\section{Author details}

${ }^{1}$ Laboratory of cytogenetic and reproductive biology, Hopital Aristide-Le-Dantec, Pasteur Avenue, PO Box 3001, Dakar, Senegal. ${ }^{2}$ Institut-Juliot-Curie, Hospital Aristide Le Dantec, Pasteur Avenue, PO Box 3001, Dakar, Senegal. ${ }^{3}$ Laboratory of anatomy and pathology, Principal military Hospital of Dakar, Nelson Mandela Avenue, PO Box 3006, Dakar, Senegal. ${ }^{4}$ Cancer Studies and Research Group in Senegal (GERCS), Cheikh Anta Diop Avenue, PO 5005, Dakar, Senegal. ${ }^{5}$ Department of Animal Biology, Faculty of Science and Technology, Postulant Unit of Genetic, Genomic and Bioinformatic of Infectious Diseases, Cheikh Anta DIOP University, PO Box 55, Cheikh Anta Diop Avenue, Dakar, Senegal. ${ }^{6}$ Immunology \& Biology of infectious diseases Unit, Institut Pasteur Dakar, 36, avenue Pasteur, PO Box 220, Dakar, Senegal.

\section{Received: 27 August 2019 Accepted: 8 April 2020} Published online: 22 April 2020

\section{References}

1. Bray F, Ferlay J, Soerjomataram I, Siegel RL, Torre LA, Jemal A. Global cancer statistics 2018: GLOBOCAN estimates of incidence and mortality worldwide for 36 cancers in 185 countries. CA Cancer J Clin. 2018;68:394-424.

2. Pankaj S, Nazneen S, Kumari S, Kumari A, Kumari A, Kumari J, et al. Comparison of conventional pap smear and liquid-based cytology: a study of cervical cancer screening at a tertiary care center in Bihar. Indian J Cancer. 2018;55:80-3.

3. Kanthiya K, Khunnarong J, Tangjitgamol S, Puripat N, Tanvanich S. Expression of the P16 and Ki67 in cervical squamous intraepithelial lesions and Cancer. Asian Pac J Cancer Prev. 2016;17(7):3201-6.

4. Moore MA. Attasara P, khuhaprema T, et al. Cancer epidemiology in mainland South-East Asia-past, present and future. Asian Pac J Cancer Prev. 2010;11:67-80

5. Singh GK, Miller BA, Hankey BF, Edwards BK. Persistent area socioeconomic disparities in U.S. incidence of cervical cancer, mortality, stage, and survival, 1975-2000. Cancer. 2004;101:1051-7.

6. Ginindza and Sartorius. Projected cervical Cancer incidence in Swaziland using three methods and local survey estimate. BMC Cancer. 2018;18:639.

7. Sharma M, Bruni L, Diaz M, Castellsague X, de Sanjose S, Bosch FX, Kim JJ. Using HPV prevalence to predict cervical cancer incidence. Int J Cancer. 2013;132(8):1895-900.

8. Bruni L, Diaz M, Castellsague X, Ferrer E, Bosch FX, de Sanjose S. Cervical human papillomavirus prevalence in 5 continents: meta-analysis of 1 million women with normal cytological findings. J Infect Dis. 2010;202(12):1789-99.

9. Whitham HK, Hawes SE, Chu H, Oakes JM, Lifson AR, Kiviat NB, Sow PS, Gottlieb GS, Ba S, Sy MP, Kulasingam SL. A comparison of the natural history of HPV infection and cervical abnormalities among HIV-positive and HIVnegative women in Senegal, Africa. Cancer Epidemiol Biomark Prev. 2017; 26(6):886-94.

10. Munoz N, Bosch FX, Castellsaque X, Diaz M, de Sanjose S, Hammouda D, et al. Against which human papillomavirus types shall we vaccinate and screen? The international perspective. Int J Cancer. 2004;111:278-85.

11. Mboumba Bouassa RS, Prazuck T, Lethu T, Meye JF, Bélec L. Cervical cancer in sub-Saharan. Africa: an emerging and preventable disease associated with oncogenic human papillomavirus. Med Sante Trop. 2017;27(1):16-22.

12. Bruni L, Albero G, Serrano B, Mena M, Gómez D, Muñoz J, Bosch FX, de Sanjosé S. ICO/IARC Information Centre on HPV and Cancer (HPV Information Centre). Human Papillomavirus and Related Diseases in Senegal. Summary Report 17 June 2019.

13. Mansour T, Limaiem F. Cancer, cervical screening. StatPearls [internet]. Treasure Island (FL): StatPearls Publishing; 2019.

14. Marie-Cécile Vacher-Lavenu. La revue du Praticien 2001. 51;1417-1423.

15. Ferlay J, Ervik M, Lam F, Colombet M, Mery L, Piñeros M, Znaor A, Soerjomataram I, Bray F. Global Cancer observatory: Cancer today. Lyon, France: International Agency for Research on Cancer; 2018. Available from: https://gco.iarc.fr/today.

16. Ferlay J, Soerjomataram I, Ervik M, et al. Cancer Incidence and Mortality Worldwide: IARC CancerBase No.11. Lyon: International Agency for Research on Cancer. 2015;Available from: http://www.wcrforg/int/ cancer-factsfigures/data-specific-cancers/cervical-cancer-statistics.

17. SY-Diallo M, Faye O, Mbaye E.H.S, Diallo A. S, Gueye M. V, Diop N, IOP N, DEM A. Dépistage primaire du Cancer du Col de l'utérus par frottis cervico vaginal et Typage HPV dans le district de Mbao au Sénégal. Journal de la Société de Biologie Clinique du Bénin. 2016;№ 025;9-13.

18. Mbaye El HS, Gheit T, Dem A, McKay-Chopin S, Toure-Kane NC, Mboup S, Tommasino M, Sylla BS, Boye CS. Human papillomavirus infection in women in four regions of Senegal. J Med Virol. 2014;86(2):248-56.

19. DEM A. DIENG MM. TRAORE B. GAYE M. DIOP M. TOURE P. Les carcinomes épidermoïdes du col utérin à l'Institut du cancer de Dakar. Université Cheik Anta Diop (Ucad), Dakar Sénégal. 2008;Cahiers Santé vol. 18, nº 1.

20. Somé OR, Zongo N, Ka S, Wardini R, Dem A. Pap smear for mass screening: results of an African experiment. Gynecol Obstet Fertil. 2016;44(6):336-40.

21. Afoutou JM, Diallo AS, Silou J, Faye O, Abong R, Alipio R, Cissé ML, Diouf A, Cissé CT, Afoutou JFK, Moreau JC, Diawo Bah M, Anthonioz PH, Corréa P. Une décennie de dépistage colpocytologique au CHU de Dakar. Journal des Sciences J. M. Afoutou et al / J. Sci. 2008;8(№ 2):1-16.

22. Diallo AS, Sam Giao M, Fenton CE, Afoutou JM. Condyloms, dysplasia and carcinomas of cervix : a twenty years experience (1980 - 1999). Dakar Med. 2003:48(3):181-4.

23. Xi LF, Touré P, Critchlow CW, Hawes SE, Dembele B, Sow PS. Kiviat NB prevalence of specific types of human papillomavirus and cervical. squamous intraepithelial lesions in consecutive, previously unscreened, west-African women over 35 years of age. Int J Cancer. 2003;103(6):803-9.

24. Kassa RT. Risk factors associated with precancerous cervical lesion among women screened at Marie Stops Ethiopia, Adama town, Ethiopia 2017: a case control study. BMC Res Notes. 2018;20;11(1):145.

25. Zidi S, Sahli M, Mezlini A, Yacoubli-Loueslati B. Association of Combined Tobacco Smoking, Hormonal Contraceptive use and Status Matrimonial with Cervical Cancer Evolution in Tunisian Women. Pathol Oncol Res. 2018. https://doi.org/10.1007/s12253-018-0442-4.

26. Iversen L, Sivasubramaniam S, Lee AJ, Fielding S, Hannaford PC. Lifetime cancer risk and combined oral contraceptives: the Royal College of General Practitioners' Oral Contraception Study. Am J Obstet Gynecol. 2017;216(6): 580.e1-9.

27. Roura E, Travier N, Waterboer T, de Sanjosé S, Bosch FX, Pawlita M, et al. The influence of hormonal factors on the risk of developing cervical Cancer and pre-Cancer: results from the EPIC cohort. PLoS One. 2016;11(1):e0147029.

28. Vaisy A, Lotfinejad S, Zhian F. Risk of cancer with combined oral contraceptive use among Iranian women. Asian Pac J Cancer Prev. 2014; 15(14):5517-22.

29. Phaliwong P, Pariyawateekul P, Khuakoonratt N, Sirichai W, Bhamarapravatana K, Suwannarurk K. Cervical Cancer detection between conventional and liquid based cervical cytology: a 6-year experience in northern Bangkok Thailand. Asian Pac J Cancer Prev. 2018;19(5):1331-6.

30. Thapa N, Shrestha G, Maharjan M, Lindell D, Maskey N, Shah R, Ge C, Cai H. Burden of cervical neoplasia in mid-western rural Nepal: a population-based study. J Gynecol Oncol. 2018;29(5):e64.

31. Manzo-Banales HM, Ordaz-Lopez VI, Martinez-Avena AE, Cerda-Rivera PE, Ochoa MC, Ramirez-Leyva DH. Diagnostic Concordance between Cytology, Colposcopy and Biopsy in Cervical Cancer in Chihuahua. Mexico. Austin J Obstet Gynecol. 2016;3(3):1064.

32. Melinte-Popescu A, Costachescu G. The degree of agreement between HPV testing, pap smear and colposcopy in cervical dysplasia diagnosis. Rev Med Chir Soc Med Nat lasi. 2012;116:536-9.

33. Oh EJ, Jung CK, Kim DH, Kim HK, Kim WS, Jin SY, Yoon HK. Fellowship council and Committee of Quality Improvement of the Korean Society for Cytopathology. Current cytology practices in Korea: a Nationwide survey by the Korean Society for Cytopathology. J Pathol Transl Med. 2017; 51(6):579-87.

34. Islam S, Uddin MN, Saleh FM. Histological and cytological correlation of cervical Cancer and precancerous lesions in a tertiary Hospital in Bangladesh. Mymensingh Med J. 2016;25(4):674-80.

35. Önder SAKIN, Kadir GÜZELMERIÇ, Bülent KARS, Orhan ÜNAL. Clinical significance of cervical low-grade squamous intraepithelial lesions: 8 years' experience. J Kartal TR. 2016;27(2):129-33.

36. Dasari P, Rajathi S, Kumar SV. Colposcopic evaluation of cervix with persistent inflammatory pap smear: a prospective analytical study. Cytojournal. 2010;7:16.

37. Jones S, Sykes P, Pather S, Peddie D. Is there a role for colposcopy in the follow-up of treated low grade squamous intraepithelial lesions? Aust N Z J Obstet Gynaecol. 2004;44(6):574-6.

38. Holowaty P, Miller AB, Rohan T, To T. Natural history of dysplasia of the uterine cervix. J Natl Cancer Inst. 1999;91:252-8. 
39. Ostör AG. Natural history of cervical intraepithelial neoplasia: a critical review. Int J Gynecol Pathol. 1993;12:186-92.

40. Shaki O, Chakrabarty BK, Nagaraja NA. Study on cervical cancer screening in asymptomatic women using Papanicolaou smear in a tertiary care hospital in an urban area of Mumbai. India J Family Med Prim Care. 2018;7(4):652-7.

41. Cortes C, Gonzalez E, Morales J, Poblet E. Genotype as prognostic factor in cervical intraepithelial neoplasia grade I lesions. J Turk Ger Gynecol Assoc. 2017;18:1-8.22.

42. Jahic M, Jahic E. Diagnostic approach to patients with atypical squamous cells of undetermined significance cytological findings on cervix. Med Arch. 2016;70(4):296-8.23.

43. Pretorius RG, Peterson P, Azizi F, Burchette RJ. Subsequent risk and presentation of cervical intraepithelial neoplasia (CIN) 3 or cancer after a colposcopic diagnosis of CIN 1 or less. Am J Obstet Gynecol. 2006;195:1260.

44. Fatih MF, Veli M, Taner M, Nurhan U, Derya T. Evaluation of pap-smear results of patients who applied to our obstetrics and gynecology clinic. Okmeydanı Tıp Dergisi. 2012;28:142-5.

45. Clavel C, Dalstein V, Birembaut P. Stratégies de dépistage des lésions précancéreuses du col de l'utérus : cytologie ou test HPV? Rev Francophone des Lab. 2008:405:57-65.

\section{Publisher's Note}

Springer Nature remains neutral with regard to jurisdictional claims in published maps and institutional affiliations.

Ready to submit your research? Choose BMC and benefit from:

- fast, convenient online submission

- thorough peer review by experienced researchers in your field

- rapid publication on acceptance

- support for research data, including large and complex data types

- gold Open Access which fosters wider collaboration and increased citations

- maximum visibility for your research: over $100 \mathrm{M}$ website views per year

At BMC, research is always in progress.

Learn more biomedcentral.com/submissions 